\title{
El Discurso Político de Manuel de Salas: Criterios para el Presupuesto Reformista de Chile en el Contexto Independentista Latinoamericano ${ }^{1}$
}

\author{
The Political Discourse of Manuel de Salas: \\ Criteria for the Reformist Budget in \\ Chile in the Latin American Independentist Context \\ O Discurso Político de Manuel de Salas: \\ Critérios para o Postulado Reformista do \\ Chile no Contexto Independentista Latino-Americano
}

\author{
Alejandra Leal Ladrón de Guevara ${ }^{2}$ \\ Universidad Austral de Chile, sede Puerto Montt - Chile \\ alejandraleal@spm.uach.cl
}

Recepción: 31/10/2012

Evaluación: 10/06/2013

Aceptación: 15/05/2014

Artículo de Revisión de Caso

\section{RESUMEN}

A partir de la heterogeneidad cultural y las necesidades vitales de los pueblos del territorio chileno a principios del siglo XIX, como en todos los reinos de América, existe el anhelo de organizarse como una nación libre (Escobar, 1976). No obstante, priorizando las acciones políticas para ello puede entenderse que la permanencia del Rey de España Fernando VII en el poder pudo ser considerado como un beneficio para el crecimiento económico de Chile. De manera tal, en este estudio se recoge el pensamiento político e ilustrado de Manuel de Salas (1754-1841) y en él se exponen descriptivamente los conceptos de la identidad y la definición de la autonomía política como dos criterios para la institución del gobierno, instaurados a través de la acción de los patriotas en la lucha por la libertad. De igual modo, se analizan los principios que estabilizan al Estado chileno para el autogobierno, en el que Salas sostiene que la estabilidad dependerá de las relaciones comerciales con

1 Este trabajo es resultado del proyecto de investigación Discursos Políticos de Criollos Ilustrados en las Independencias Americanas (código SGI: 1128), avalado por el Consejo Superior de Investigaciones Científicas (CSIC) y la Universidad Pedagógica y Tecnológica de Colombia (UPTC). Esta investigación fue desarrollada por el grupo Ilustración en América Colonial (ILAC), reconocido y visible por Colciencias.

2 Doctora en Ciencias Humanas, mención Lingüística y Literatura por la Universidad Austral de Chile. Actualmente se desempeña como académica de esta universidad, desarrollando actividades de investigación en pedagogía y análisis del discurso. 
otros Estados tan solventes como parecía serlo España. En consecuencia, se proyecta que el desarrollo de las acciones de Salas tiene los efectos propios del pensamiento ilustrado, ya que la nación y el Estado van definidos por argumentos inspirados en la Declaración de los Derechos del Hombre y del Ciudadano (1789), tales como la justicia y la piedad, la seguridad y la dignidad del hombre, medidas por la resistencia y la opresión: los fundamentos valóricos que en el contexto americano movilizaron la revolución.

Palabras clave: Revista Historia de la Educación Latinoamericana, Manuel de Salas, independencia, Chile.

\begin{abstract}
From the cultural heterogeneity and the vital needs of Chilean people in the beggining of the nineteenth century -as in all kingdoms of America- there is the desire to be organized as a free nation (Escobar, 1976). However, giving priority to the politic actions to do so, it can be understood that the permanence of the Spanish King Fernando VII in the power could be considered as a benefit to the economic growth in Chile. Thus, in this study the political and illustrated thought of Manuel de Salas (1754-1841) is gathered. In Salas' work the concepts of the identity and the definition of the political autonomy are exhibited descriptively as two criteria for the institution of the government, restored across the action of the patriots in the struggle for the freedom. In the same way, there is analyzed the beginning that stabilize the Chilean state for the self-government, in which Salas said that stability depends on trade relations with other states as solvent as well it seemed to be Spain.
\end{abstract}

Consequently, there is projected that the development of Salas' actions had the characteristic effects of the enlightened thinking, since the nation and the State are defined by arguments inspired in the declaration of the human rights and of the citizen (1789), such as justice and piety, security and the dignity of man, measured by oppression resistance: the fundamental values that mobilized revolution in the American context.

Key words: Journal of the education Latin American history, Manuel de Salas, independence, Chile.

\section{RESUMO}

A partir da heterogeneidade cultural e das necessidades vitais dos povos do território chileno em princípios do século XIX, como em todos os reinos da América, existe o desejo de organizar-se como uma nação livre (Escobar, 1976); não obstante, priorizando as ações políticas para ele, pode entenderse que a permanência do Rei da Espanha Fernando VII no poder pode ser considerada como um benefício para o crescimento econômico do Chile. Desta maneira, neste estudo se recorre ao pensamento político e ilustrado de Manuel de Salas (17541841) e nele se expõem descritivamente os conceitos da identidade e da identificação da autonomia política como dois critérios para a instituição do governo, instaurados através da ação dos patriotas na luta pela liberdade. De igual modo, se analisam os princípios que estabilizam ao estado chileno para o autogoverno, em que Salas sustentam que a estabilidade dependerá das relações comerciais com outros estados tão responsáveis como parecia ser a Espanha. Em conseqüência, se projeta que o desenvolvimento das ações de Salas tem os efeitos próprios do pensamento ilustrado, já que a nação e o estado são definidos por argumentos inspirados na Declaração dos Direitos do Homem e do Cidadão (1789), tais como a justiça e a piedade, a seguridade e a dignidade do homem medidas pela resistência à opressão: os fundamentos valorosos que no contexto americano mobilizaram a revolução.

Palavras-chave: Revista História da Educação Latino-americana, Manuel Salas, independência, Chile. 


\section{INTRODUCCIÓN}

Cabe señalar que los escritos de Manuel de Salas y Corbalán (1754-1841) son el referente de un discurso político comprometido con la causa libertaria de la independencia de Chile (1810-2010). De estos se destacan los memoriales escritos en diferentes momentos de su vida pública; sin embargo, en el período de la independencia y la reconquista española, este se declara a favor de los derechos ciudadanos desde la isla Más a Tierra (actual Robinson Crusoe del Archipiélago Juan Fernández). De acuerdo con el estudio contextual de Chile en la historia de América Latina durante los primeros años del siglo XIX, se evidencian tanto el valor de la justicia social como el derecho inalienable a la libertad, promulgados en tres escenarios de la vida política que es necesario establecer: el primero, correspondiente al discurso enmarcante del contexto de la Revolución francesa; el segundo, del enmarcado en América Latina, y el tercero, aquel que se gesta al interior del reino o territorio-país.

En esta línea, los escritos memoriales de Manuel de Salas, creados durante su destierro junto a más de 40 patriotas en la isla Más a Tierra (1814-1817), obedecen a los resultados de una profunda reflexión en torno al contexto de la revolución, ya que desde allí se proyecta en un discurso vehemente para reformular los derechos ciudadanos que trascienden al pensamiento de distintas instancias de la historia y la geografía nacional. Por lo tanto, cerciorarse de cómo funcionan los contextos político y filosófico en el fenómeno socio-cultural de la historia global de este período es un claro reflejo de lo que acontece en la historia local que, en su conjunto, facilita la explicación de los principios del derecho y el concepto de la patria, del Estado y de la nación para Chile (Zavala, 1953). ${ }^{3} \mathrm{~A}$ fin de cuentas, el discurso salista será sostenido en el contexto político y social americano, apoyado por un fuerte contenido prospectivo de la economía y del bien común.

Así pues, el objetivo general de este texto comprende la declaración de los criterios discursivos e ideológicos que definen el presupuesto político para Chile en el contexto latinoamericano a partir del naciente siglo XIX. La metodología contempla la reflexión acerca del pensamiento político reformista de Salas, coexistiendo con la mirada integradora del ideario americano, esto es, el movimiento subyacente entre los países latinoamericanos. En primera instancia, se justifica el uso del discurso memorial dirigido por Salas al Virrey del Perú, José Fernando Abascal (1814), donde se plantea el pensamiento político visionario opuesto al discurso del poder realista, estableciendo las diferencias y los vínculos entre las necesidades de la comunidad (el pueblo) y la formación del sentido patrio con las correspondientes fronteras geopolíticas para Chile en relación a América Latina. En definitiva, se promueve que el discurso salista transforma el referente de la revolución (1814-1817) y proyecta el discurso social con vigencia real y prospectiva para el "presupuesto reformista" de la nación entre las naciones americanas para el primer tercio del siglo XIX.

3 Zavala sostiene que la crisis del absolutismo político de fines del siglo XVIII da pie a las ideas igualitarias y democráticas en América como, además, la recepción de las ideas ilustradas, ya que a partir del siglo XIX nace el sentimiento americano. Por ello, vale decir que "ese ambiente engendra a los caudillos de la independencia". Ver más en Silvio Zavala, Hispanoamérica septentrional y media, período colonial (México: EDIMEX, 1953), 128. Además, respecto a las clases y razas se fomentan "los principios de libertad e igualitarios que defiende la ilustración". En fin, valores que otorgan el fundamento humanista a los Estados americanos. Zavala, Hispanoamérica, 144. 


\section{Escenarios en la construcción del discurso político de Manuel de Salas}

\subsection{La identidad y la autonomía: argumentos del discurso memorial}

Conforme a lo anterior, hay que añadir los conceptos de la identidad y la definición de la autonomía política como dos criterios para la institución del gobierno de Chile. Estos se instauran en las voces de los patriotas como rasgos incuestionables para alcanzar la libertad. Si bien un hecho que es considerado el acto cautelar de la justicia, la identidad del pueblo, como, también, la autonomía para actuar como un gobierno libre, está observado en la instalación de la Junta de Gobierno de 1810. Este acontecimiento es recapitulado por Manuel de Salas en el memorial ${ }^{4}$ enviado al Virrey del Perú José Fernando Abascal, en 1814. ${ }^{5}$ Pues, allí se vuelcan las razones que facilitaron la instalación de la Junta y el paso clave hacia la independencia de Chile. Este argumento se puede leer detalladamente en el escrito de Salas que, sin querer justificar los actos de desarraigo del gobierno precedente, explica todas las acciones bajo la premisa del deber y la obediencia a los principios que cautelan la conformación del Estado. Hay que agregar que esto se expone con los motivos de la espontánea abdicación del poder del rey en manos del pueblo. Así pues, Salas mantiene ya desde 1808 la convicción de que la base para gobernar es la instauración de una Junta, la cual debe estar aliada con los estamentos del Estado. Aunque esto opera funcionalmente como un recurso para hacer operativo el Estado de Chile, en él se justifica el hecho puntual de la instalación de la Primera Junta de Gobierno acaecida dos años después de la Junta de Vecinos del país, devolviendo este valor al gobierno centrado en el Estado. ${ }^{6}$

De esta manera, los argumentos que se generan en el memorial están supeditados al principio de la identidad y la definición de la autonomía política. ${ }^{7}$ De acuerdo con ello, Salas es el enunciador colectivo que enumera y potencia cuatro razones que tuvieron los pueblos para la instalación de la Junta de Gobierno de 1810, estas son: la ausencia del rey español, la disolución de la ligazón entre la metrópoli y el pueblo, la desconfianza generada por las intrigas entre el gobierno, como, además, la adhesión de los empleados del reino a los franceses. Si bien estas son razones políticas, sirvieron para comunicar los fundamentos con el fin de darse un gobierno libre y autónomo sobre el cual se cimentarían los demás grupos fundacionales de la economía, la educación, la agricultura o la naciente industria lino. ${ }^{8}$ Sin embargo, un

$4 \quad$ El memorial entendido como un texto de circulación jurídica, por consiguiente, un documento social. Martín Alonso. Enciclopedia del idioma. Diccionario histórico y moderno de la Lengua Española (Siglos XII al XX), vol. 2 (Madrid: Aguilar, 1958 ), 1593.

5 "El memorial es un texto argumentativo cuya base histórico-cultural trasciende desde la Filosofía a la Ilustración”. Además, en el contexto de la conquista y la colonia en América, la práctica del mismo lo define como un instrumento de comunicación, es decir, en una práctica compartida con las bases filosóficas y culturales que, a su vez, se valida en el tiempo como un discurso de carácter oficial. Alejandra Leal, "Documento memorial: desde la Filosofía a la Historia de América", Revista Austral de Ciencias Sociales, no. 15 (2008): 33-34.

6 No obstante, Amunátegui comenta de sus lecturas sobre Salas "que su autor era una realista sincero i fervoroso", pues "el 30 de mayo de 1778, día de San Fernando, fue admitido a besar las augustas manos de las personas reales" y "el 25 de diciembre del mismo año, vió comer al rei. Sin embargo, aquel fidelismo vasallo había de volver a Chile a fomentar, sin advertirlo i sin quererlo, el espíritu revolucionario". Miguel L. Amunátegui, Los precursores de la Independencia de Chile, vol. 3 (Santiago de Chile: Imprenta, Litografía i Encuadernación Barcelona, 1910), 350.

7 La pertinencia de los actos de habla y la adecuación a las reglas de la discusión dialéctica son aspectos esenciales para determinar la validez de los argumentos. Martínez considera que las diversas argumentaciones están en relación con los tipos de contextos de acción en los que se realicen. El análisis de los esquemas argumentativos relacionados con la construcción del razonamiento en el discurso, más los efectos que se espera conseguir en el enunciatario, se ligan a la demostración y al razonamiento matemático, adaptándose a un contexto de práctica real, cuyo propósito persuasivo busca demostrar la verdad. Por ejemplo, cuando Salas expone en el memorial al rey que "Chile, instaló su Junta, después de una espontánea abdicación del mando que el jefe del reino hizo en el Pueblo, lo que aleja la temeraria inculpación de insurgencia” (Salas L., Memorial 1, párrafo 2, 1914), esto asegura que la verdad tiene su precedente en un hecho real, de manera que las definiciones de identidad deberán ser claras como las definiciones normativas, por ejemplo, la Declaración de los Derechos Humanos, pues los argumentos de reciprocidad, cuya regla es la justicia, otorgan importancia al precedente. María Martínez, Análisis del Discurso (Cali: Ediciones Universidad del Valle, 2005), 17-18.

8 La manera en que la libertad, por un lado, comienza a ser entendida como una forma natural del ser de la naciente época y, 
El Discurso Político de Manuel de Salas:

Criterios para el Presupuesto Reformista de Chile en el Contexto Independentista Latinoamericano

quinto argumento evalúa el gobierno de García Carrasco, de quien Salas asegura que no manifestó la suficiente entereza para frenar situaciones que obstaculizaron el movimiento por la independencia del país; además de esto, la denuncia del interés personalista y beligerante de los hermanos Carrera.

\section{Los principios que estabilizan al Estado chileno}

En torno a los principios que estabilizan al Estado para el autogobierno, Manuel de Salas sostiene que estos se encuentran supeditados a las necesidades de los reinos. Aunque la heterogeneidad cultural de los pueblos lo impedía, a principios del siglo XIX, en todos los reinos de América, existió el anhelo de organizarse como una nación libre. ${ }^{9}$ No obstante, priorizando las necesidades, puede entenderse que la permanencia del Rey de España Fernando VII en el poder pudo ser considerado como un beneficio para el crecimiento económico de Chile. En consecuencia, la estabilidad del Estado en parte dependerá de las relaciones comerciales con otros Estados tan solventes como parecía serlo España, ahora con Colombia y luego, con los del resto de América.

Sin ir más lejos, el desarrollo del pensamiento político de Salas topa techo en la Ilustración, ${ }^{10}$ pues para él es en la nación en donde se implica la paz entre todas las comunidades del país, la cual devuelve la estabilidad en un contexto que promueve la integración y el desarrollo de todas las instituciones solventes. Si bien Chile contaba con la libertad, si no constitucional, por lo pronto era otorgada por el derecho natural, un aspecto fundamental para dar sentido a la organización política del país. ${ }^{11}$ No se debe olvidar a Amunátegui (1910) cuando plantea que:

\section{En la asamblea de 1811 templaron sus armas dos hombres que influirian poderosamente en la organización politica de Chile: don Bernardo O'Higgins y don Manuel de Salas. El primero ilustraría dentro de poco el nombre de caudillo de la revolución, mientras que el último merecería el título de precursor de la Independencia. ${ }^{12}$}

Como antecedente, en 1808 Salas renuncia ante el Presidente García Carrasco al cargo de Director de la Academia de San Luis, para accionar en la Junta de los doce vecinos, a partir de la cual se irían gestando las nuevas ideas que justificarán la primera Junta de Gobierno de 1810. Asimismo, la existencia de un territorio propio y estable para impulsar el mejoramiento

por otro, como la acción concebida en la creación de la Junta de Gobierno de 1810; también lo es el auge progresita en diversas áreas de desarrollo ; entonces todo ello ha de ser la antesala para la formación de la institucionalidad del Congreso de 1811 y la Constitución de 1812, en la cual también colabora Manuel de Salas que, en su conjunto, serían las instancias que cimentarán el sentido de la independencia de España, del Virreinato del Perú y del despotismo. Alejandra Leal, "Los memoriales de Manuel de Salas: Argumentos para la Independencia de Chile", Cuadernos de Historia, no. 30 (2009): 29-42. De igual modo, el crecimiento intelectual va apoyado por el desarrollo de la economía, el comercio y industria textil, pues propone a su Majestad el apoyo para el cultivo del lino, así dirá: “...fomento de la agricultura, ninguno más practicable, ni mas propio para atender el comercio de este reino, que el cultivo del lino." Amunátegui, Miguel L. Los precursores de la Independencia de Chile. Vol. 3. Santiago de Chile: Imprenta, Litografía i Encuadernación Barcelona, 1910: pág. 423.

9 A decir verdad, antes de la organización independiente, existía en las colonias americanas "una tendencia a la interpretación del derecho divino como fundamento del Estado". Roberto Escobar, La Filosofía en Chile (Santiago: Universidad Técnica del Estado de Chile, 1976), 23.

10 Sin embargo, desde Platón preexiste la batalla entre el derecho y la fuerza. Ernst Cassirer, Filosofía de la Ilustración (México: Fondo de Cultura Económica, 1997), 262.

11 Se debe recordar que, durante el gobierno de los hermanos Carrera (1812), Salas pasa a formar parte de la comisión encargada de examinar, discutir y rectificar el proyecto de la Constitución Política de Chile. Miguel L. Amunátegui, Escritos de Don Manuel de Salas y Documentos relativos a Él y a su Familia (Santiago de Chile: Imprenta, Litografía y Encuadernación Barcelona, 1914 ), 393.

12 En la medida que la Ilustración concede privilegios del conocimiento, para Salas equivale a ser llamado "impulsor" y, por qué no, "forjador del ideario independentista de Chile" en el contexto latinoamericano. Alejandra Leal, Tesis doctoral: Análisis del discurso de los memoriales de Manuel de Salas en Juan Fernández (1814-1817) (Valdivia: Universidad Austral de Chile, 2006), 380. Alejandra Leal, Manuel de Salas: contextos para la Historia de Chile (Santiago: RIL Editores, 2010), 102. 
de la comunidad habitante de Chile no estuvo libre de dificultades, ya que la identidad de la nación implicaría la integración de los valores, costumbres, principios y la lengua. ${ }^{13}$ De igual forma, se debe recordar que, durante el gobierno de los hermanos Carrera (1812), Salas pasa a formar parte de la comisión encargada de examinar, discutir y rectificar el proyecto de la Constitución política de Chile. ${ }^{14} \mathrm{Si}$ bien un Estado se hace legítimo para gobernar una nación por la optimización de las relaciones internas, también lo hará por las exteriores con países benignos para las transacciones como el caso de España y Colombia. Esta cuestión cuenta en la formación de las bases constitucionales en cuyos proyectos participa activamente en el plan de gobierno para las constituciones de 1811 y la de 1812; como también en el notable hecho de las decisiones públicas previas al 18 de mayo de 1818 en donde, por decreto, el Director Supremo Bernardo O'Higgins lo nombra en la comisión de los siete ciudadanos que redactarán un proyecto de constitución provisoria que regirá al Estado hasta la realización del Congreso. Además, para fortalecer su espíritu en la apreciación de Chile de que, de estar hasta el momento desamparada, podía en el futuro llegar a ser el más rico de los reinos, Miguel Luis Amunátegui dirá que: "Salas habia visto en sus viajes con el estado a que Chile se hallaba reducido ... una de las comarcas más desvalidas y atrasadas del orbe, cuando podía ser una de las mas ricas i felices".$^{15}$

Así también, sin ir en desmedro de todo lo que ya se estaba haciendo, Salas se muestra como un hombre visionario que, debido a los disturbios generados a partir de la Revolución francesa y con la declaración de los derechos ciudadanos del 26 de agosto de 1789, se proyecta con la esperanza de desconectarse radicalmente de la monarquía española; una causa fundamental en la dilatación del progreso de Chile y el continente americano. Si bien, el 21 de diciembre de 1823, Salas llega a ser el encargado de los negocios para el canje de ratificaciones en el tratado de unión entre Colombia y Chile, permite al pueblo soñar con la paz necesaria para brindarse el tan anhelado desarrollo. ${ }^{16}$

Recapitulando, las bases de la democratización serán representativas del pueblo al contar con una persona como Jefe de Estado, elegido por votación de la mayoría en el sano ejercicio del derecho a voto. No obstante, esta identidad de país no está completa en la medida que no se cuenta con la autonomía política en las gestiones económicas del territorio, ${ }^{17}$ pues esto será válido para Chile en la medida que pueda conservar la unidad y la certeza de que las decisiones contarán con el apoyo de todos quienes conforman la nación, es decir, de toda la comunidad que comparte ese mismo territorio. ${ }^{18}$

En la formulación de un aspecto del pensamiento político de Salas, se dirá que la existencia real del territorio habilita el contexto situacional donde la credibilidad de los miembros representativos del poder de España son los garantes de la libertad de los pueblos americanos. No obstante, el clima beligerante es un factor que impide el legítimo desarrollo del país. Así también, la optimización de las relaciones exteriores será un factor de la estabilidad territorial

13 Se debe hacer notar que el concepto de nación implica en su definición los componentes valorativos y los sentimientos patrios vigentes en los antecedentes históricos compartidos por la comunidad. Jorge Pinto, "La formación del Estado y la Nación en el pueblo Mapuche”, en De la inclusión a la exclusión. El estado, la nación y el pueblo mapuche (Santiago: DIBAM y Centro de Investigaciones Diego Barros Arana, 2003), 17.

14 Amunátegui, Escritos de Don Manuel de Salas, 393.

15 Amunátegui, Los precursores, 355.

16 Amunátegui, Escritos de Don Manuel de Salas, 399.

17 Retomando la premisa anterior, la ideología política de la libertad tuvo su origen en el empirismo y el racionalismo de los ingleses entre los siglos XVI y XIX. Julián Marías, Historia de la Filosofía (Madrid: Revista de Occidente S.A, 1956), 17.

18 Manuel Atria, Teoría general del derecho, lógica e informática jurídicas (Valparaíso: Sociedad chilena de filosofía jurídica y social, 1987), 374, 375 
El Discurso Político de Manuel de Salas:

Criterios para el Presupuesto Reformista de Chile en el Contexto Independentista Latinoamericano

de Chile; como, además, la representatividad del pueblo en la persona del Jefe de Estado confirmaría la autonomía para un gobierno político.

De acuerdo con lo anteriormente expuesto, América cuenta con los antecedentes que construyen la regla de precedente para las Américas en la independencia de las 13 colonias de los EE.UU. el 4 de julio de 1776, así como en la declaración francesa de los derechos del hombre y del ciudadano declarados el 26 de agosto de 1789; lo que, en consecuencia, no debiera admitir la existencia de los presos políticos. ${ }^{19}$ En resumen, en nombre de este bien común, Salas cumple la función de pedir la libertad y la devolución de las posesiones, pues estos derechos son expresados con un argumento de autodefinición, es decir, de la identificación comunicativa del enunciador solicitante y del destinatario en el contexto histórico que los priva de sus derechos en el presidio de la isla; así como la necesidad de generalizar para Chile la autonomía política para gobernarse y el derecho adquirido entre los interlocutores debido a la justicia precedente, pues, estos serán los elementos que justifican la coherencia de los actos sociales y parte de los presupuestos de la historia para la reforma de Chile. ${ }^{20}$ De esta manera, el memorial enviado al Virrey en 1814 ilustra y recupera información de las falencias del régimen despótico de los gobiernos precedentes; así también, la falta de criterio al juzgar deliberadamente a cualquier ciudadano; del mismo modo, se invalidan los derechos de ciudadanía como el natural e inalienable derecho a la libertad; al mismo tiempo, el de cesión voluntaria de la soberanía con el propósito de ser gobernados y el de resistirse a la opresión de un gobierno tirano. Igualmente, se verifican tanto los respaldos como los refuerzos que conducen a aceptar la coherencia argumentativa en donde se declara la creencia de que la existencia de un territorio libre es garante de un contexto situacional para gobernar; así como de la credibilidad de los miembros representantes del poder; ${ }^{21}$ de igual manera, la optimización de las relaciones exteriores acreditada por el desarrollo del país; la representatividad del pueblo en la persona del Jefe de Estado por el derecho legítimo de la votación y, también, la autonomía política en las gestiones del territorio de un país como Chile, que amerita la necesidad de tomar decisiones por su propia cuenta, aunque no se cuente con el rey español.

En general, diversos son los antecedentes que permiten reconocer a Manuel de Salas, durante su vida pública, como un miembro activo de varias instituciones de beneficencia y de otras que acreditaban el crecimiento del país. Algunos corresponden a la participación en las acciones políticas junto a O’Higgins Vallenar en 1798, en la Hermandad de la Caridad de Santiago iniciada el 31 de octubre de 1804; asimismo, a partir de la Sociedad Económica de Amigos del País creada en 1813 y, pues, también lo será de la Sociedad Amigos de Chile; más tarde, promoviendo la creación de una nueva sociedad filantrópica, la cual es iniciada en 1818, entre otras tantas acciones que, de manera abierta, escindieron cualquier fundamento de la filosofía y de la política autónoma para el sentido abierto de país. ${ }^{22}$ Por lo mismo, los argumentos del

19 Este particular episodio, no obstante, presenta ciertos hechos que alteran el curso de lo que pudo haber sido en el ejercicio del bien común; pues Salas acusa en su memorial a Mariano Osorio, que publica a escondidas en el mismo junio de 1814 la Ordenanza Real para otorgar la libertad a los insurgentes; por el contrario, tres meses después envía al Rey el 18 de noviembre de 1814 la lista de los llamados revolucionarios con la orden del envío al seguro presidio dispuesto. Juan Fernández y Guillermo Feliú, Colección de Historiadores y de Documentos relativos a la Independencia de Chile, vol. XXXV (Santiago: Cultura de Chile: Imprenta, 1950), 13.

20 Al respecto, Félix Laviña (1987) sostiene que el proceso histórico hacia los derechos humanos ha sido la historia moral de la humanidad; por el otro, en la búsqueda de estos derechos, el hombre marca el camino natural conducente a la verdad, respondiéndose las preguntas universales presentes en el desarrollo de todas las culturas y las civilizaciones, en Sistemas internacionales de protección de los Derechos Humanos. (Buenos Aires: Ediciones Depalma), 5.

21 Se debe decir que, antes de la organización de un Estado independiente en las colonias americanas, existía "una tendencia a la interpretación del Derecho Divino como fundamento del Estado". Roberto Escobar, La Filosofía en Chile (Santiago: Universidad Técnica del Estado de Chile, 1976), 23.

22 Pedro Henríquez Ureña (1949) plantea que, a partir de estos hechos sociales, se hace peligroso para la autoridad tradicional las lecturas de los filósofos como la posteriormente traducida al español Declaración de los Derechos del Hombre, promulgados por la 
citado memorial obedecen a la fuente de un pensamiento común; aquellos que circulan con el propósito de contar con la libertad, a cambio de justificar la necesidad de ser hombres libres en un contexto histórico y social que promueve el crecimiento para todas las comunidades de la nación.

\section{Manuel de Salas y los efectos del pensamiento ilustrado}

\subsection{La libertad para la acción: nación y Estado}

Como se ha señalado, a partir del derecho divino de los hombres, nace el derecho a poseer la libertad. En el memorial enviado al Virrey del Perú, Salas rectifica que el reino no debe responder a nadie por esta gestión. La historia general deja ver que la libertad es una necesidad para los pueblos de América, los cuales ya aspiraban a constituir su independencia. ${ }^{23}$ En consecuencia, si cabe alguna duda al pensar en que Salas participa activamente en la Junta de Gobierno movilizado por algún acto revolucionario, se puede sostener que estos tuvieron el propósito de formar el equipo de gobierno necesario para instaurar las bases del Estado, ya que el territorio había sido cedido por el Rey a los pueblos de América para conformarse en naciones independientes. ${ }^{24}$

A raíz de esto, se prueba que Salas era un ciudadano libre que no traicionó sus ideales. De esta manera, se comprende que no puede haber traición cuando se conocen los derechos y la acción de constituir un Estado de gobierno legítimamente aprobado, cuestión que absuelve a los patriotas de aquella temeraria culpa. Así se va probando un discurso político que conduce nuevos movimientos hacia la consolidación de la nación conformada por un territorio también libre. Además, de un gobierno que se proyecta hacia la seguridad política centralizada con las alianzas para fortalecer el gobierno, se da paso a la conformación del Congreso. No obstante, este proyecto se ve ensombrecido por los ataques dirigidos por los hermanos Carrera al incipiente gobierno, lo cual provoca otra lucha, tanto o más ingrata: la de verse envueltos en una guerra fratricida.

\subsection{La justicia y la piedad: dos valores para la libertad}

El único principio que allana el camino hacia la igualdad entre los hombres es la libertad. Por lo mismo, Salas toma nuevos bríos para acusar y también para exigir aquello que les es tan esquivo: la libertad de los presos políticos en Juan Fernández. Es por ello que este enunciador colectivo aclara estas ideas a su receptor, el Virrey del Perú. Por un lado, conoce que la condición de reo en un hombre no lo ilegitima de la justicia y la igualdad entre los hombres; por otro, su formación de abogado le permite apelar a la benigna piedad del Virrey Abascal, con la convicción de que un acto de tal naturaleza dignificaría su naturaleza soberana. ${ }^{25}$

asamblea constituyente de París y leídos primeramente en Bogotá por Antonio Nariño (1794) y, luego, en buena parte de América; en Historia de la Cultura en la América hispánica (México: Fondo de Cultura Económica), 61.

23 Nogueira y Cumplido desarrollan el concepto de Estado jurídico, agregando que, para que este se conformara, fue necesario que la sociedad evolucionara y se organizara distinguiéndose en ella fundamentos: económicos, religiosos, filosóficos, políticos y culturales; por cierto, ideales que se inician con el período independentista. Humberto Nogueira y Francisco Cumplido, Derecho político: introducción a la política y teoría del estado (Santiago: Universidad Andrés Bello, 1987), 82.

24 Alejandra Leal, "Los memoriales de la libertad", en Sociedad y cultura: reflexiones transdisciplinarias (2007): $171,178$.

25 De acuerdo al concepto de los derechos atribuidos al rey este contaría con todas las atribuciones; no obstante, el proceso de cambios vivido por el pueblo merecía contar con acciones virtuosas apoyadas en la cortesía y la piedad. Fritz Kern, Derechos del rey y derechos del pueblo (Madrid: Biblioteca del pensamiento actual, Ediciones Rialp, 1955), 9. 
El Discurso Político de Manuel de Salas:

Criterios para el Presupuesto Reformista de Chile en el Contexto Independentista Latinoamericano

\section{La seguridad y la dignidad del hombre}

¿No es acaso la seguridad el derecho garante del Estado otorgado a los hombres libres? Es evidente que el discurso de Salas se desarrolla en un contexto que expulsa la garantía del Estado de derecho, es decir, de un Estado libre. Esto es pensar que el pueblo está inspirado en los principios de la libertad y la justicia para la ciudadanía. Por la convicción que demandan estos fundamentos precedentes, el comunicador del memorial exige ser escuchado. Ser atendido implica ser evaluado ante lo que se plantea y, de ello, se guarda la conciencia de que, tras la evaluación, él y los demás saldrán absueltos de cualquier culpa. Si la convicción de que lo realizado es producto de la elaboración del pensamiento reflexivo, se podrá afirmar que los componentes activos de la ciudadanía han dado un traspié a estos principios que valoran la dignidad. En este sentido, las lecturas de Salas escudriñan en cada detalle de la declaración francesa de 1789 donde se plantea que solo ante el delito, el hombre puede ser arrestado o detenido. ${ }^{26}$ Por ello, la voz colectiva representada en la persona de Manuel de Salas también es la conciencia de un pueblo que no ha cometido más delito que procurar su libertad y, como consecuencia, vivir con dignidad. ${ }^{27}$ Esto último es expresado por Salas en el memorial enviado al general del ejército realista don Mariano Osorio en febrero 14 de 1815: "Dígnese Usía mandarme poner en un punto que reúna mi seguridad, mi cómoda existencia y la facilidad de escucharme ${ }^{\prime 2}{ }^{28}$ Sin agregar nada más, se puede sostener que Salas actúa inspirado en la fuente de la verdad encontrada en el manantial de las ideas ilustradas. Es la vitalidad que mantiene despierta la esperanza, regando los espíritus de los otros presos con la nobleza de la palabra suavizada a los oídos por el noble eco de la libertad.

\section{La resistencia y la opresión: una política de la hermandad}

De acuerdo con esto, se dirá que Salas conoce el significado de la patria, el lugar donde crece la verdad y se fortalecen los sueños. Esto proyecta la manera más idónea de gestarse en ese territorio que bien conoce: una patria propia, en donde todo está por comenzar. Por una parte, son hechos concretos los que declaran las acciones interrumpidas por la revolución. Esto permite activar el recuerdo del proyecto en curso de tantos nombres como el de Salas y el de fray Camilo Henríquez, quienes hicieron frente a la opresión, resguardada en las trincheras de la ignorancia y el miedo. Son ejemplos de este enfrentamiento: la educación ofrecida a la gente en los talleres de trabajo comunitario, la enseñanza dirigida a los mendigos para acercarse a la beneficencia, la creación de los lazos de hermandad entre los pueblos vecinos de América, el cultivo del comercio, de la minería y del ganado; en fin, un sinnúmero de acciones para el motor del crecimiento de la nación que lentamente fue matando la revolución. Por otra parte, Manuel de Salas comparte estos ideales y los defiende con un discurso poderoso, el que no se deja avasallar por el miedo ni menos por la ignorancia. En el memorial enviado al general del ejército realista don Mariano Osorio en febrero 14 de 1815, Salas declara su espíritu combativo y defensor de la nación y del Estado; es por ello acusatorio ante las vilezas de los que buscaban la destrucción de un país que se forjaba con los puños de la nobleza de los hombres de bien. Los fragmentos ilustrados

26 Desde la perspectiva del Derecho Político, Laviña sostiene que "el objetivo de toda asociación política es la conservación de los derechos naturales e imprescindibles del hombre. Estos derechos son: la libertad, la propiedad, la seguridad y la resistencia a la opresión", en Sistemas internacionales, 8.

27 Considerado un derecho constitucional, dirá Urzúa para referirse a los derechos de ciudadanía. Germán Urzúa, Manual de Derecho Constitucional (Santiago: Editorial Jurídica de Chile, 1991), 104, 105.

28 Sin embargo, existe una contradicción que se debe aclarar. Según consta en el Archivo de la Biblioteca Nacional, el 1 de junio de 1814 es enviada desde Madrid la Real Orden sobre la conducta que debe seguirse con los insurgentes de Chile, firmada por el procurador Lardizábal al Señor Gobernador Capitán General de entonces don Mariano Osorio, la cual afirma que "no deben ser tratados como unos delincuentes", que "basta que su conducta de presente se observe y cele" y, además, "se les pide gozar de la libertad civil y seguridad individual”. Feliú, Colección de Historiadores, 138. 
de los memoriales exhiben las falencias en el régimen de los gobiernos precedentes a la revolución, los cuales sobrepasan los límites de las naciones americanas.

Por esa hermandad, las lecturas de Manuel de Salas están en el documento aprobado por la Asamblea Nacional de la Declaración de 1789, pues, toda asociación política es la conservación de los derechos naturales e imprescindibles del hombre, vigentes en la libertad, la propiedad, la seguridad y a la consecuente resistencia a la opresión. De este modo, el ejercicio de los derechos del ser humano no tendrá otros límites que los garantizados en la búsqueda de la verdad: el pilar para la independencia latinoamericana.

\section{CONCLUSIÓN}

De esta manera, se asevera que Salas es un hombre que tiene un concepto de nación unificada y exenta de juicios excluyentes, en la medida que la fidelidad de los pueblos está puesta en la causa del progreso. Por consiguiente, se dirá que si la naturaleza humana está constituida en la nación, la sabiduría no queda demarcada a la geografía ni es propia de un tiempo histórico; será, por cierto, la naturaleza humana que se impondrá en las naciones.

En suma, para definir el discurso político libertario de Manuel de Salas, se debe sostener que detrás están las teorías político-filosóficas ilustradas que dan sentido a la realización de un gobierno autónomo en el territorio, la nación y el Estado, propiamente tales. A partir de estos presupuestos teóricos, se infiere que el derecho divino de los reyes se complementa con el derecho divino de los hombres, pues esta voluntad de ser libres impulsa a Salas hacia una nueva ideología, entendida como la voluntad conciliatoria para todos los pueblos de su nación, ya que la misma unidad de los pueblos será el facilitador de ese gobierno libre.

Se ha planteado que el memorial, estudiado en el contexto de la Conquista y la Colonia en América, es un tipo de discurso argumentativo oficial de una colectividad, basado en una teoría del derecho y orientado a la acción social, cuya función comunicativa reconstruye la historia del pensamiento político reformista para Chile. De esta manera, se concilian los tres escenarios contextuales del pensamiento político de Salas: el enmarcante de la Revolución francesa; el segundo, del enmarcado en América latina y el tercero, aquel que se gesta al interior del reino o territorio-país.

Complementariamente, el servicio al estado está transparentado por la utilidad que reciben los pueblos de la nación. Salas complementa sus acciones en aras de su formación académica fuertemente ilustrada en la filosofía y el derecho político, asimismo, en los posteriores servicios al Estado y a los pueblos de la nación chilena. Se infiere, por esto, que los conceptos de Estado y nación están en función del servicio comunitario. Así también, el deseo de servicio de sus ideales de Estado trascienden al territorio, pues es un concepto de Estado americanista por el cual se cruzan las fronteras con un solo propósito: la libertad americana.

Es evidente que el discurso filosófico y político de los derechos ciudadanos adquiridos formalmente por él se amalgaman con la experiencia de sus lecturas y viajes en diversos territorios americanos y del mundo político europeo. Esto permite afirmar que la sabiduría de Salas se centra en la naturaleza humana, sustentado en los hechos de la historia que unifica a los hombres de la patria. No obstante, la justicia y la piedad son dos fuertes valores que lo acercan a la igualdad. Luego de escudriñar en cada detalle la Declaración francesa (1789), el discurso salista se desarrolla en un contexto que expulsa la garantía del Estado de derecho, pues se convierte en la voz colectiva de los expatriados en la isla del destierro. 
Para complementar, la patria, considerada un hecho histórico-político y geográfico, ha sido guiada por el amor a la humanidad e invitada a conservar la integridad de sí con los elementos materiales y espirituales; aunque hoy se entenderá el surgimiento del Estado con expresos presupuestos implicados en la filosofía, las bases históricas de la política, la historia y la cultura. En consecuencia, se proyecta que, en el discurso de este gestor de la independencia, se destaca por la mirada integradora que transforma el referente de la revolución (1814-1817), con vigencia real y prospectiva para el "presupuesto" de la nación como de las naciones americanas para el primer tercio del siglo XIX hasta la Constitución de 1823, pues, en el gobierno del ministro Diego Portales, se compartirán las ideas de Salas, el primer político que visionó la economía, dirá Sepúlveda (1955), ${ }^{29}$ en un contexto de la modernidad para Chile.

En conclusión, se sostendrá que Manuel de Salas y Corbalán es uno de los fundadores del pensamiento libertario y de quien solo resta reconocer el valor de su acción visionaria, lo cual contribuye a abrir los horizontes de la palabra en un contexto donde algunos no tuvieron miedo a proclamar la libertad para el pueblo como el derecho fundamental del hombre americano.

\section{REFERENCIAS}

Alonso, Martín. Enciclopedia del idioma. Vol. 2, Diccionario histórico y moderno de la Lengua Española (Siglos XII al XX). Madrid: Aguilar, 1958.

Amunátegui, Miguel L. Escritos de Don Manuel de Salas y Documentos relativos a Él y a su Familia. Santiago de Chile: Imprenta, Litografía y Encuadernación Barcelona, 1914.

Amunátegui, Miguel L. Los precursores de la Independencia de Chile. Vol. 3. Santiago de Chile: Imprenta, Litografía i Encuadernación Barcelona, 1910.

Atria, Manuel. Teoría general del derecho, lógica e informática jurídicas. Valparaíso: Sociedad chilena de Filosofía Jurídica y Social, 1987.

Cassirer, Ernst. Filosofía de la Ilustración. México: Fondo de Cultura Económica, 1997.

Escobar, Roberto. La Filosofía en Chile. Santiago: Universidad Técnica del Estado de Chile, 1976.

Feliú, Guillermo. Colección de Historiadores y de Documentos relativos a la Independencia de Chile. Vol. XXXV. Santiago de Chile: Imprenta Cultura, 1950.

Figgis, John N. Derecho Divino de los Reyes y tres ensayos adicionales. México: Fondo de Cultura Económica, 1942.

Henríquez Ureña, Pedro. Historia de la Cultura en la América hispánica. México: Fondo de Cultura Económica, 1949.

Kern, Fritz. Derechos del rey y derechos del pueblo. Madrid: Biblioteca del pensamiento actual, Ediciones Rialp, 1955.

Laviña, Félix. Sistemas internacionales de protección de los Derechos Humanos. Buenos Aires: Ediciones Depalma, 1987.

Leal, Alejandra. "Contextos para la historia de Chile". Contextos, Estudios de Humanidades y Ciencias Sociales, no. 26 (2011): 97-112.

29 Refiriéndose al ministro Portales, Sepúlveda dirá que debieron pasar veinte años para que, lejos de la anarquía, la nación comenzase "a llevar a la práctica muchas de las ideas económicas de Manuel de Salas". Héctor Sepúlveda, El Mito Portaliano (Clave de nuestro destino histórico) (Santiago de chile: Ediciones del Instituto de Investigaciones Históricas Diego Portales, 1955), 55. 
Leal, Alejandra. "Documento memorial: desde la Filosofía a la Historia de América". Revista Austral de Ciencias Sociales, no. 15 (2008): 33-44.

Leal, Alejandra. "Los memoriales de la libertad". En Sociedad y cultura: reflexiones transdisciplinarias Valdivia: edición de la Escuela de Graduados de la Facultad de Filosofía y Humanidades de la universidadAustral de Chile, (2007): 171-178.

Leal, Alejandra. "Los memoriales de Manuel de Salas: Argumentos para la Independencia de Chile". Cuadernos de Historia, no. 30 (2009): 29-42.

Leal, Alejandra. Manuel de Salas: contextos para la Historia de Chile. Fondo del Libro y la Cultura. Santiago: RIL Editores, 2010.

Leal, Alejandra. Tesis doctoral: Análisis del discurso de los memoriales de Manuel de Salas en Juan Fernández (1814-1817). Valdivia: Universidad Austral de Chile, 2006.

Marías, Julián. Historia de la Filosofía. Madrid: Revista de Occidente S.A., 1956.

Martínez, María. Análisis del Discurso. Cali: Ediciones Universidad del Valle, 2005.

Nogueira, Humberto y Francisco Cumplido. Derecho político: introducción a la política y teoría del estado. Santiago: Universidad Andrés Bello, 1987.

Pinto, Jorge. "La formación del Estado y la Nación en el pueblo Mapuche". En De la inclusión a la exclusión. El estado, la nación y el pueblo mapuche. Santiago: DIBAM y Centro de Investigaciones Diego Barros Arana, 2003.

Salas Errázuriz, Juan R. (Presb.). Escritos de Don Manuel de Salas y Documentos relativos a Él y a su Familia. Santiago de Chile: Imprenta, Litografía y Encuadernación Barcelona, 1910.

Salas Lavaqui, Manuel. Escritos de Don Manuel de Salas y Documentos relativos a Él y a su Familia. Santiago de Chile: Imprenta, Litografía y Encuadernación Barcelona, 1914.

Sepúlveda, Héctor. El Mito Portaliano (Clave de nuestro destino histórico). Santiago de Chile: Ediciones del Instituto de Investigaciones Históricas Diego Portales, 1955.

Urzúa, Germán. Manual de Derecho Constitucional. Santiago: Editorial Jurídica de Chile, 1991.

Zavala, Silvio. Hispanoamérica septentrional y media, período colonial. México: EDIMEX, 1953.

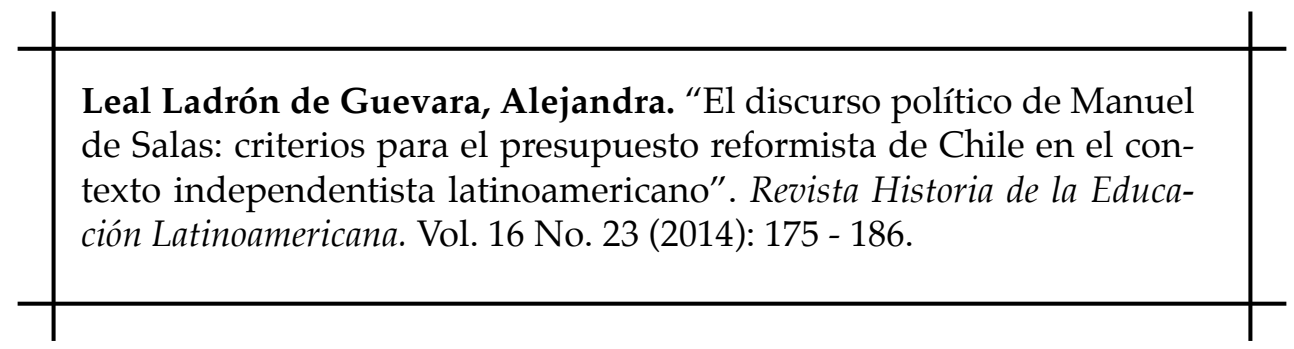

